\title{
Influências de Marcia Pompeo Nogueira no Teatro Comunitário do Canto em Floripa
}

\author{
Juliano Borba ${ }^{1}$ \\ Marilde Juçara da Fonseca² \\ Tânia Farinon ${ }^{3}$ \\ Vicente Macedo 4 \\ Agnes Sanfelici ${ }^{5}$ \\ Ana Socorro Ramos Braga ${ }^{6}$
}

Recebido em: 20/04/2020

Aprovado em: 05/05/2020

DOI: 10.5965/2358092521232020039

1 Doutor em Teatro pela Universidade do Estado de Santa Catarina (UDESC). Pesquisador do Laboratório de Uso Sustentável da Terra em Países em Desenvolvimento (Sustainable Land Use in Developing Countries) do Zalf - Leibniz-Centre for Agricultural Landscape Research, Muncheberg, Alemanha. E-mail: julianoborba@ gmail.com

2 Grupo Teatro Comunitário do Canto da Lagoa, Florianópolis - SC. E-mail: marilde. jf@gmail.com

3 Licenciada e Bacharel em Teatro pela Universidade do Estado de Santa Catarina (UDESC). E-mail: taniafarinon@gmail.com

4 Grupo Teatro Comunitário do Canto da Lagoa, Florianópolis - SC. E-mail: vicente65@hotmail.com

5 Doutora em Letras pela Universidade Federal do Rio Grande do Sul (UFRGS). Professora da Prefeitura Municipal de São José - SC. E-mail: agnessanfelici@gmail.com

6 Doutora em Teatro pela Universidade do Estado de Santa Catarina (UDESC). Professora Adjunta do Departamento de Artes Cênicas da Universidade Federal do Maranhão (UFMA). E-mail: anasocorrobraga1@gmail.com 


\section{RESUMO}

O teatro comunitário em Florianópolis tem uma história aliada à efervescência ocasionada pela sucessão de projetos e eventos diversos como cursos, seminários, oficinas, publicações, interações entre comunidades e com movimentos sociais organizados por Marcia Pompeo Nogueira durante sua carreira enquanto professora da Universidade do Estado de Santa Catarina e enquanto principal referência nesta modalidade do teatro no Brasil. A partir de sua prática e pesquisa, Florianópolis se tornou um campo fértil para experimentações teatrais de base comunitária que passaram a acontecer em vários bairros da cidade. O Teatro Comunitário do Canto se constitui seu mais longevo projeto de parceria e continua atuante após sua morte ocorrida em 2019. Neste artigo, escrito coletivamente, alguns de seus integrantes buscam em suas memórias as bases dos ensinamentos da mestra como um caminho de continuidade.

Palavras-chave: teatro comunitário, teatro na comunidade, Marcia Pompeo Nogueira, Teatro Comunitário do Canto

\section{ABSTRACT}

Community theatre in the city of Florianópolis has a history connected to the effervescence from the succession of projects and diverse events such as courses, seminars, workshops, publications, interactions between communities and with social movements organized by Marcia Pompeo Nogueira during her career as a professor at Santa Catarina State University - Udesc and as the main reference to this theatre model in Brazil. From her practice and research, Florianópolis has become an ideal field for research and experimentation on community theatre. From her practice and research, Florianópolis became a fertile field for community-based theat- 
rical experiments that started to happen in several neighborhoods of the city and some municipalities in the state of Santa Catarina. Teatro Comunitario do Canto group is her longestrunning partnership project and remains active after her death in 2019. In this article written collectively, some group members seek in their memories the bases of the master's teachings as a path for continuity.

Keywords: community theatre, theatre in community, Marcia Pompeo Nogueira, Teatro Comunitário do Canto.

\section{INTRODUÇÃO}

O presente artigo é uma organização da memória de alguns participantes do grupo de Teatro Comunitário do Canto da Lagoa sobre a relação destes com a professora Marcia Pompeo Nogueira, da Universidade do Estado de Santa Catarina (UDESC), falecida em agosto de 2019. Ele busca dar voz a estes participantes que foram tocados por Marcia e se reconhecem no teatro na comunidade, campo de investigação da referida professora. Em função disso as vozes se alternam. Alguns participantes recorreram a textos previamente escritos como suporte de suas reminiscências, outros contribuíram com fragmentos das situações vividas nos projetos e eventos organizados por ela, tais como cursos, seminários, oficinas, encontros. O texto está organizado do seguinte modo: como o grupo nasceu; relato de experiência de estágio; relato de sua experiência de pesquisa; oficinas intensivas, extensivas e, na parte final, o relato da última participação de Marcia, desta vez como diretora do grupo, abrindo um novo campo de experimentação artística e estudo de linguagem. Os subtítulos revelam como foi feita a escrita coletiva do texto em conexão com as diferentes formas de interação.

Nas palavras da própria Marcia (NOGUEIRA, 2008), o teatro na comunidade é uma modalidade teatral de difícil definição, uma vez que adquire diferentes formatos e é ligado a distintas instituições e finalidades. Ele acontece a partir de diversificadas 
práticas sejam elas políticas, movimentos sociais, religiosas etc. Com todos esses campos ela atuou buscando construir a transformação social junto com as pessoas. Para o Teatro Comunitário do Canto, algumas características se destacam e ajudam a compor uma noção própria dessa modalidade teatral: abertura a novos integrantes interessados em fazer teatro; a opção pelo teatro passa pela adesão ao grupo e ao que quer comunicar por meio do teatro; convívio comunitário poético; pesquisa e reflexão dos temas relevantes para a comunidade que dialoga, como o bairro, a cidade, o estado e a vida em sociedade. O processo de síntese dessas características foi em grande medida através do contato com sua prática e sua teoria.

\section{UM CANTO CHEIO DE HISTÓRIA}

A história do Grupo de Teatro do Canto da Lagoa começa em 1994, no interior de uma Escola Pública Municipal de Educação Infantil chamada de $\mathrm{NEI}^{7}$, situada no Canto da Lagoa, da qual eu, Marilde Fonseca, fui diretora. O Canto da Lagoa é um bairro que se situa às margens da Lagoa da Conceição, na parte leste da antiga ilha do Desterro. A escola fica situada na principal via de acesso, na estrada geral, entre a lagoa e a montanha.

Eu conheci a Marcia Pompeo em 1986, quando ela era coordenadora pedagógica e eu professora na Escola Sarapiquá. Aprendi muito com ela durante o ano que trabalhamos juntas, especialmente a importância da participação das famílias na escola. Ela me mostrou como organizar um mutirão, como planejar uma reunião de pais e mães de forma democrática, sem perder os objetivos; a planejar com atenção e traçar objetivos claros. Desse modo, aprendi a coordenar uma festa e manter a alegria dessa festa garantindo a participação do máximo de pessoas desde o seu planejamento até o final do encontro. Nas mais diferentes situações, ela se colocava no lugar do outro. O

7 A sigla NEI significa Núcleo de Educação Infantil (NEI), no bairro Canto da Lagoa, situado próximo ao Posto de Saúde. 
olhar nos olhos, as vezes demoradamente, e como muito afeto era o modo pelo qual ela fazia a escuta atenta.

Quando assumi a direção do NEl do Canto, iniciei o processo de construção do Projeto Político Pedagógico da Escola (PPP). Acho importante salientar que vivíamos um momento de grande participação popular na Prefeitura de Florianópolis, na gestão do prefeito Sérgio Grando (1993-1996), que mobilizou uma proposta democrática e participativa da sociedade. Em 1994, na construção do PPP envolvemos toda a comunidade escolar aqui entendida como os alunos e suas as famílias, os professores e a equipes de apoio. Havíamos constatado que em virtude da chegada de novos moradores oriundos de outros estados do Brasil estava acontecendo uma transformação muito rápida e profunda nos costumes e no cotidiano das pessoas nativas e que seria importante trazer à luz este tema. O resultado dessa abordagem temática foi a primeira peça de teatro do grupo que se chamou Uma História da Ilha. Foi um trabalho que surgiu dentro da sala de aula da Educação Infantil e cresceu e envolveu praticamente todo o bairro. Nessa peça, Marcia estava na plateia, mas havia contribuído com indicações de leituras, e com estagiários da Universidade do Estado de Santa Catarina (Udesc) que auxiliaram a comunidade do Canto a contar sua história. Este foi o caso de Reonaldo M. Gonçalves (Nado) que criou algumas letras de músicas cantadas durante a peça e juntou-se ao grupo desde então. Outra contribuição veio da Associação de Pais e Professores que contratou o professor de música Vicente Macedo, pelo reconhecimento da necessidade de musicalização para as crianças pequenas (FONSECA, 2000).

Já no ano seguinte, mais dois estagiários, Nara Wedekin e Pedro llgenfritz, contribuíram para a criação de uma encenação para a Festa Junina inspirada no casamento caipira e na festa do divino. Desta vez, a peça se chamou A História de Antigamente, pois foi inspirada nos bailes que aconteciam no Canto da Lagoa. No relato nas rodas de conversa, as pessoas mais velhas contavam que os rapazes do Canto da Lagoa ficavam indignados porque os rapazes da Barra da Lagoa vinham de canoa e "ficavam" 
com as "raparigas"8 do Canto da Lagoa. Na história criada para o teatro, eles chegavam de barco. O namoro de um casal ficou sério e a menina engravidou. O pai da moça era o festeiro da Festa do Divino e ele aproveitou essa festa para fazer o casamento da filha. Para contar este enredo, o grupo recebeu a participação de artistas populares, amigos e moradores de outros bairros próximos. A peça foi apresentada na frente da Escola e depois na festa Junina da Associação de Moradores do Porto da Lagoa.

Ao longo dos anos o teatro se consolidou no projeto pedagógico, envolvendo as famílias e os moradores que contribuíram com suas histórias, suas brincadeiras de representar, de contar e cantar. Desse modo, a professora Marcia foi fazendo o que ela mais gostava de fazer: de um lado, aproximar os alunos da Universidade do mundo real na comunidade, oferecendo oportunidade de com ela dialogar por meio do imaginário. Do outro, trazer os pais e as mães para esse universo do imaginário, encontrando ali as codificações para refletirem juntos o mundo em que seus filhos viviam e que gostariam de construir com eles. Ela oferecia a todos a possibilidade de dançar, cantar, imitar, brincar e de ser criança também.

Até o ano de 2010, os trabalhos de teatro realizados na escola se constituíram quase que exclusivamente como a única possibilidade de vivenciar o teatro no bairro. Os temas eram escolhidos com as crianças e as famílias delas, sempre procurando constatar o que realmente tinha significado para os envolvidos. O grupo de teatro que se constituiu daquelas primeiras iniciativas enfrentou períodos de latência e desmobilização. Embora não tendo deixado de se encontrar, os encontros tornaram-se eventuais, principalmente entre 1997 e 2000. Nesses momentos de latência, o projeto de Brinquedoteca ${ }^{9}$ funcionava como catalisador das leituras da realidade e do imaginário, que Marcia alimentava indicando autores. No início dos anos 2000, o desafio

80 termo rapariga na linguagem popular açoriana diz respeito a moça jovem.

9 Financiada por meio de projeto enviado à Associação Brasileira de Brinquedotecas (ABRINQ). 
foi chamar o grupo novamente para retomar o trabalho teatral. Ao longo do tempo o grupo se tornou independente embora mantendo vínculo com o espaço escolar, seu lugar de encontro, onde realizar ensaios e apresentações na quadra nas festas escolares ou em estreias, quando a relação se inverte, é o grupo que convida a comunidade para apreciar seu novo processo de trabalho. A vinculação é voluntária e aberta à comunidade sem inscrição prévia. Os encontros do grupo ocorrem semanalmente às quintas feiras. Seus participantes entram e saem conforme as suas disponibilidades, interesses e etapas da vida, ou retornam em momentos especiais de apresentação de um novo trabalho, conforme demonstraremos adiante.

\section{EXPERIÊNCIA DE ESTÁGIO EM TEATRO NA COMUNIDADE}

Em 2012, eu, Tânia Farinon e minha colega de curso Rachel Chula decidimos fazer estágio juntas e fomos apresentadas ao Teatro Comunitário do Canto no mês de março, quando decidimos com o grupo fazer uma remontagem da primeira obra realizada pelo grupo "Uma História da Ilha" de 1994.

A ideia partiu do desejo da própria comunidade, o que tornava tudo mais pessoal e significativo. Apenas dois integrantes do grupo estavam naquela primeira montagem de 1994: Vicente Macedo, fundador e diretor musical do grupo e Marilde Fonseca, que permanecia diretora naquela época. Todos estavam confiantes que o tema chamaria muitas pessoas para fazer teatro e isso possibilitaria a reestruturação do grupo.

Embora houvesse entusiasmo da nossa parte, registrado no nosso projeto e nos planos dos encontros, estes não se concretizavam pois não havia participantes. Diante desse desafio, percebemos que a dificuldade maior era a desmobilização do grupo. Naquele momento estava muito difícil reunir um grupo de adultos interessados em fazer teatro. As professoras da escola se mobilizaram para chamar a comunidade através de bilhetes, e uma faixa foi fixada no muro da escola para chamar novos 
integrante, mas nada funcionou. Marcia, então supervisora de estágio, interveio em um dos encontros e foi fundamental para o projeto seguir outro rumo. Segundo ela, era necessário atrair as pessoas com uma ação significativa para a comunidade. A Festa Junina era uma atração cultural e, portanto, seria eficaz para motivar a participação comunitária.

A partir dessa sugestão, novos bilhetes foram enviados para os pais convidando-os a fazer parte da encenação da festa junina. Desta vez funcionou. No encontro seguinte, me surpreendi ao encontrar cerca de doze pessoas. As estagiárias expuseram as ideias para a encenação e ouviram histórias da própria comunidade com relação aos casamentos que aconteciam antigamente. Desta vez, alguns participantes contaram sobre noivas que eram roubadas pelos pretendentes e, assim, a família da noiva não era obrigada a pagar a festa. Não havia festa, nem casamento, pois a moça já havia sido levada pelo futuro marido. Usando essa história como base, foi iniciado o processo de criação da peça a partir do teatro imagem, uma das técnicas do Teatro do Oprimido, de Augusto Boal. As imagens a princípio eram congeladas e em seguida ganhavam vida e se ligavam umas às outras, resultando em quatro cenas: Família do noivo (gaúcha) e a família da noiva (nativa); Serenata para a noiva; A fuga; e o casamento civil. O grupo optou pela realização de um casamento no final. Os atores que fizeram o papel de noivos eram casados na realidade, o que facilitou a interação.

A encenação do casamento foi a atração final da festa junina da escola e toda a comunidade adorou. 


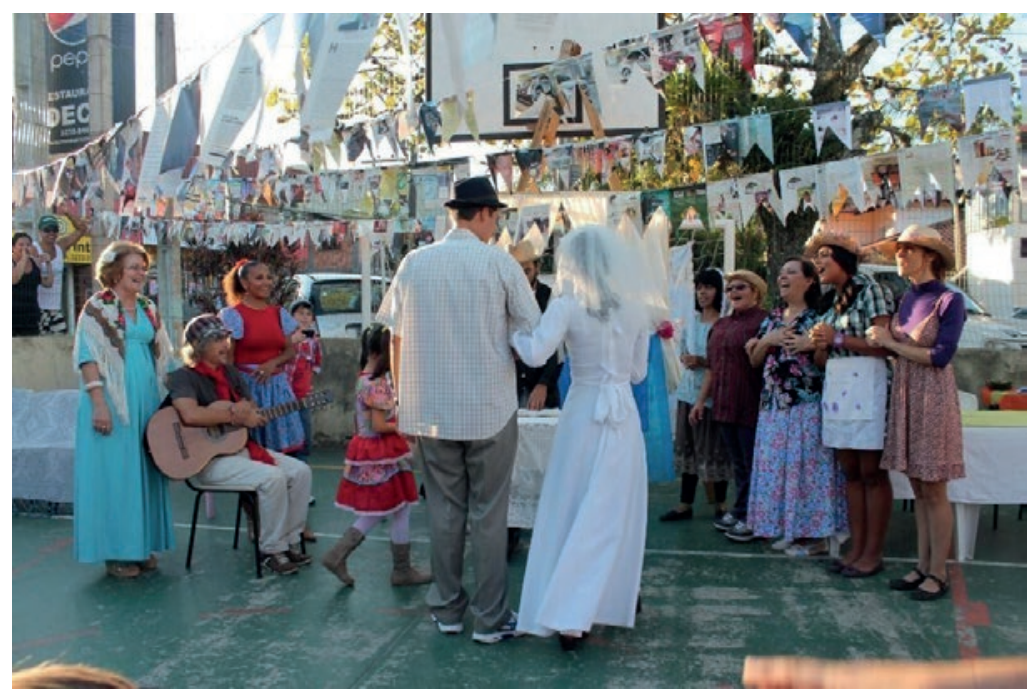

Figura 1: Cena do Casamento

Fonte: Acervo Tânia Farinon (2012).

No segundo semestre, o nosso trabalho consistiu em ouvir o que a comunidade tinha para oferecer e criar o roteiro de cenas. Vários desafios vieram à tona, como a falta de concentração dos adultos e controle das crianças e os temas abordados, com os quais nem sempre todos os integrantes estavam à vontade.

Agregaram-se ao projeto outros dois estagiários, Joyce Andrade, que ficou responsável de desenvolver o processo com as crianças, e Rafael Reüs, que auxiliou no processo de criação e construção da montagem da peça De Quem É Essa Terra. A estreia aconteceu primeiramente no Centro de Artes (CEART/UDESC) e, na semana seguinte, na própria escola, tendo como cenário a Lagoa, num final de tarde de verão, finalizando o ano de estágio e o ano letivo. A parceria se fortaleceu entre a escola, a Universidade e o grupo de teatro, reverberando nos anos seguintes. 


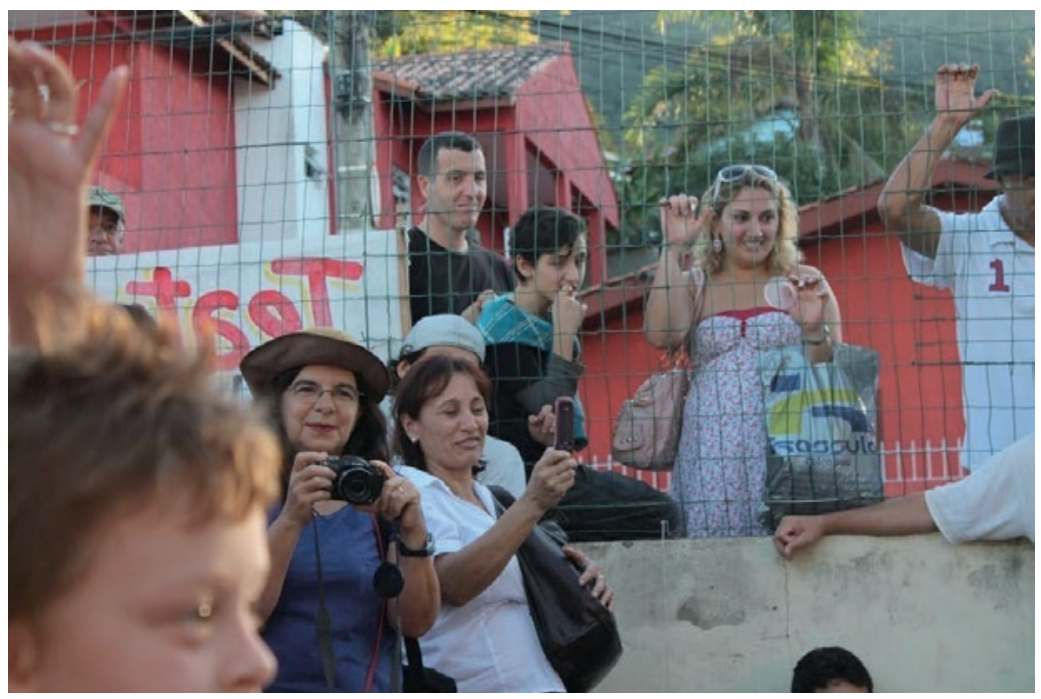

Figura 2: Marcia Pompeo Nogueira fotografando a apresentação.

Fonte: Acervo Tânia Farinon (2012).

\section{OFICINAS INTENSIVAS E EXTENSIVAS DE FORMAÇÃO EM TEATRO NA COMUNIDADE}

Após o retorno de seu doutorado na Inglaterra ${ }^{10}$, Marcia criou o Núcleo de Formação de Facilitadores (FOFA/UDESC) em 2003, e começou a oferecer formação para alunos da universidade e escolas públicas, pais e membros dos diversos grupos de teatro comunitário locais em duas modalidades de eventos que se tornaram tradição no campo do teatro comunitário de Florianópolis: as Oficinas Intensiva e Extensiva de Teatro na Comunidade.

A Oficina Intensiva era organizada de modo a oferecer diferentes oficinas de curta duração, entre duas e quatro horas em

10 Concluído em 2002 na University of Exeter sob orientação de John Somers e apoio de Tim Prentki da University of Winchester. 
média para os grupos comunitários da cidade e os grupos de estágio teatro na comunidade realizados por alunos da UDESC. A Oficina Intensiva acontecia em uma edição anual, geralmente em maio ou junho com a duração de um fim de semana. O formato era o seguinte: no sábado, os participantes eram recebidos com uma atividade inicial de integração envolvendo danças populares e depois eram divididos para participar das oficinas. Após o intervalo no meio da manhã e da tarde trocavam de oficina, de modo que ao final do dia teriam frequentado três oficinas diferentes. No domingo, eles se especializam em uma dessas oficinas no período da manhã, e à tarde todos os participantes se reuniam para um encerramento das atividades no Espaço I ou II do Bloco Vermelho no Centro de Artes para apresentação de um resultado ou um processo desenvolvido em cada oficina. Marcia havia se inspirado nas oficinas intensivas realizadas pela PETA - Philippines Educational Theatre Association, que ela conheceu durante seu doutorado.

As oficinas intensivas foram imprescindíveis para a formação do Grupo do Canto que participou de todas as edições, de 2003 a 2017. Nelas tivemos acesso a diferentes técnicas, gêneros e possibilidades artísticas que não teríamos no nosso mundo da Escola e do Bairro. Além de prover estímulo estético aos seus participantes, foram também oportunidades para os grupos se reconhecerem e entrarem em contato com diferentes metodologias do teatro comunitário. Reverberando com impacto ainda maior para as crianças participantes e seus pais, por meio dos contatos transformadores que aconteciam naquela universidade pública e gratuita, pois era uma materialização da possibilidade de eles estudarem ali no futuro, se assim quisessem.

Já a Oficina Extensiva era uma proposta pedagógica focadas em determinados temas ou metodologias, buscando aprofundá-la. A exemplo disso, a Oficina Extensiva de 2011, realizada em dois semestres, constituiu-se de um curso e uma mostra de teatro fórum em colaboração com o Centro de Teatro do Oprimido (CTO) do Rio de Janeiro tendo como facilitadora Helen Sarapeck. Como resultado, o Grupo do Canto montou com a direção de duas estagiárias de teatro na comunidade da Udesc, Sonia 
Laiz Vernacci Veloso, conhecida como Esha, e Heloisa Petry ${ }^{11}$ o teatro-fórum Um canto, um conto: sonhos e lutas a partir de duas histórias de mulheres na luta por respeito e direitos no casamento. Uma queria autonomia para ir e vir usando o automóvel da família e saiu em busca desse aprendizado, mas era desencorajada; a outra, não vendo saída para a convivência diária com seu marido, decidiu seguir sozinha. As duas histórias foram organizadas na tentativa de questionar as formas de atuação social das mulheres, revendo escolhas e procurando alternativas de solidariedade em que mulheres podem se apoiar no curso da vida. A montagem envolveu canto, dança e um ritual de roda de bruxas em torno de um caldeirão feminino como ingrediente agregador de capacidades, vontades e sonhos.

Explorando outras linguagens, Marcia organizou uma oficina de Teatro Playback ${ }^{12}$ em colaboração com o grupo Dionisos, de Joinville, que aconteceu na UDESC em 2013. No Teatro Playback os atores encenam de modo improvisado as histórias contadas por pessoas da plateia. O curso encantou os participantes pela sua natureza lúdica baseada na improvisação estruturada, e por causa da flexibilidade de temas que são escolhidos no diálogo dos atores com a plateia.

Em 2014, os diretores do grupo comunitário argentino Catalinas Sur, Adhemar Bianchi e Gilda Arteta, vieram a Florianópolis ministrar uma oficina durante duas semanas, dividida em seis encontros práticos e uma conversa inicial. Nesta oficina, o projeto de encenação do Teatro Comunitário do Canto foi o foco e se tornou seu eixo prático. A ideia central gerada anteriormente pelo grupo e com a direção de Juliano Borba foi desenvolvida pelos diretores argentinos. O roteiro proposto por eles aconte-

11 Sonia Laiz Vernacci Velloso é atriz, professora e é graduada e mestre em teatro pela UDESC. Heloisa Petry cursou teatro pela UDESC, se formou em psicologia pela UNISUL e fez mestrado pela UFSC.

120 PlayBack Theatre foi idealizado e desenvolvido por Jonathan Fox e Jo Salas, em 1975, nos Estados Unidos. A oficina foi liderada pela atriz Clarice Steil Siewert e contou com a participação dos demais integrantes do grupo Dionisos Teatro em alguns encontros. 
ceria através de um coro de camarões que perdiam seu espaço público para interesses individuais de um empresário do setor imobiliário, que nesse contexto entendido como o predador, que tem o apoio dos tubarões. Diante desse impasse, os camarões resolvem se unir para enfrentar o inimigo comum. O formato de peça-musical, com destaque para o coro de camarões e uma estrutura episódica e sugestiva, aparentemente longe do realismo, se mostrou de forte crítica da situação de ocupação dos espaços públicos e exploração indiscriminada dos empreendimentos imobiliários na ilha de Florianópolis.

\section{O GRUPO DO CANTO COMO CAMPO DE EX- PERIMENTAÇÃO NA PÓS GRADUAÇÃO}

Eu, Juliano Borba, vinha pesquisando o teatro comunitário argentino desde 2005 e havia morado em Buenos Aires entre 2007 e 2009 colaborando diretamente com o Grupo Catalinas Sur. Em 2014, quando ingressei no doutorado no PPGT da UDESC através da orientação de Marcia, planejei uma pesquisa de campo prática que consistiu na condução de uma montagem e circulação de espetáculo com o Teatro Comunitário do Canto, segundo características, princípios e metodologias do teatro comunitário na Argentina. A pesquisa de doutorado foi planejada para oferecer um conhecimento prático sobre essa metodologia que eu havia experimentado enquanto observador participante na Argentina em 2007 a 2009. A proposta ao grupo foi feita em março e aceita com entusiasmo por seus participantes.

A partir de 2015, submetemos a proposta de montagem ao edital Elisabete Anderle e fomos contemplados. Com o recurso financeiro o foco do trabalho passou a ser o aprimoramento da montagem que havia ganhado sua estrutura dorsal definitiva na oficina oferecida por Adhemar Bianchi e Gilda Arteta. O grupo foi dividido em diferentes comissões: dramaturgia, música, produção e cenário. Cada comissão teve um coordenador com a função de organizar, motivar e conduzir os trabalhos. As comissões se reuniam em geral às terças-feiras ou aos sábados, en- 
quanto aos ensaios aconteciam nas quintas-feiras. Preparamos as primeiras possibilidades visuais do camarão de forma simples apenas com um chapéu representando um rabo de camarão. A ideia inicial de figurino acabou permanecendo e o cenário de telões de tecido bordado emoldurados através de canos foi idealizado e construído coletivamente para ser adaptável a múltiplos espaços (BORBA, 2018).

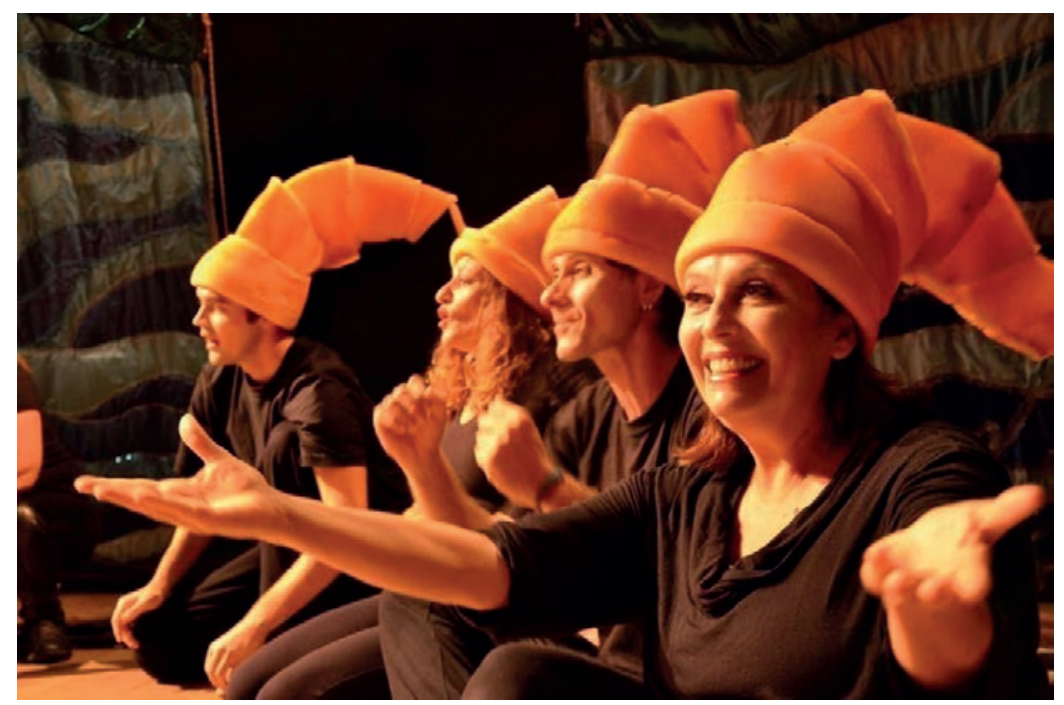

Figura 3: Apresentação no Ceart - Udesc.

Fonte: Acervo do Grupo. Foto de Eduardo Shumacher (2015).

Como resultado, a peça E se Eu Fosse Um Camarão... é um teatro-musical sobre uma "cambada" de camarões que vive na Lagoa da Conceição. O espetáculo ganhou poucos diálogos e as cenas foram organizadas em sequência de ações com base em canções parodiadas, cantadas pelos personagens em coro. Os camarões do Canto da Lagoa desfrutavam de um espaço público na beira da lagoa onde faziam suas atividades culturais. É o último espaço público que restou, pois os demais foram vendi- 
dos e privatizados por muros que abrigam casas e condomínios, impedindo o acesso da comunidade, estava prestes a virar um grande empreendimento imobiliário.

O enredo foi baseado numa história verídica sobre o campo de futebol do Palmeirinha localizado no Porto da Lagoa em que a comunidade perdeu o terreno inicialmente e depois da mobilização popular a prefeitura desapropriou o terreno e devolveu para a comunidade como espaço público. Na peça, os camarões se mobilizam para conseguir a desapropriação do terreno. Uma parte da canção de encerramento esclarece a proposta: "uma história de fantasia, na qual a ganância perdia. Isso não aconteceu, mas bem que poderiam, plantamos comunhão $e$ colhemos alegria..." (BORBA, 2018).

Nos anos seguintes, fizemos a circulação do espetáculo, apresentando nas cidades de Brusque, Anitápolis e Joinville, sempre com interesse de fortalecer causas coletivas e iniciativas comunitárias. Também foram realizadas apresentações na UDESC, no encerramento da Oficina Intensiva, na NEI do Canto da Lagoa e em outras escolas, na Universidade Federal de Santa Catarina, e na praça das Rendeiras na Lagoa da Conceição.

\section{O GRUPO DO CANTO E A EXPERIMENTAÇÃO DE MARCIA POMPEO}

Como um dos membros fundadores do Teatro Comunitário do Canto, eu, Vicente Macedo, posso dizer que, a partir da longa convivência, sempre irei lembrar de Marcia com muito carinho, por sua personalidade e presença afetuosa e gentil. Eu a conheci no tempo em que era professor de música na Escola Autonomia e dava aulas para um dos seus filhos. Ao buscá-lo na escola, ela costumava entrar e cumprimentar os professores com uma simpatia e interesse genuínos.

No final de 2017, Marcia ficou sabendo que estava com câncer e no início de 2018, afastada das atividades na UDESC, por conta da quimioterapia, escolheu assumir a direção do Grupo de Teatro do Canto da Lagoa, com assistência de Juliano Borba. 
Até então, o grupo tinha a professora Marcia como uma presença eminente, uma parceira constante e sempre disposta a encontrar soluções e oferecer possibilidades. Mas, de repente ela estava ali, real, dedicando toda sua atenção, seu tempo, seu carinho para o teatro. Logo o grupo percebeu a capacidade de percepção e escuta, de organização no planejamento, de respeito com outro e de disciplina. Marcia construía sua autoridade de maneira leve, afetiva e segura, como uma educadora que era. Foram muitos encontros de risadas, jogos, brincadeiras, rodas, músicas, danças e abraços. Ela nos ensinou a manter a alegria e a disposição mesmo quando os tempos são difíceis e incertos.

A experiência que mais me marcou positivamente foi quando Marcia, ao assumir a direção do Teatro Comunitário do Canto, no ano de 2018, por cerca de 8 meses, veio com uma proposta de ouvir o grupo e a partir dessa escuta sugeriu que fosse trabalhada a figura do analfabeto político tendo como referência do texto do poeta e dramaturgo alemão Bertold Brecht. Ela buscava refletir com o grupo o momento político que o país atravessava após o golpe contra a presidenta Dilma Rousseff em 2016 e a iminência da eleição do candidato da extrema direita Jair Bolsonaro, como de fato acabou se concretizando. A tentativa era a de buscar responder para nós mesmos, integrantes do grupo, sobre o que teria acontecido com o Brasil. Nos exercícios de vozes e tons propostos, o eco sussurrante das vozes dos analfabetos políticos se misturavam, e as perguntas de difícil resposta não calava: Como é possível que os "ratos" se congreguem novamente e tomem o poder? quem são aqueles que negam a política e por quê? como dialogamos com eles? o quê de analfabeto político permanece em nós? o analfabeto político de hoje encontra ainda correspondência no analfabeto político de Brecht?

Desde os primeiros encontros sob nova direção, percebi que não haveria oportunidade de continuar fazendo o que mais gostava, isto é, tocar violão, criar canções coletivamente, sempre em um tom de comédia/paródia. Desta vez, o assunto era mais sério e assim Marcia foi conduzindo os encontros e eu fui me afastando, uma vez que a música não estava mais presente nesses encontros. 
Então, Marcia trouxe para os ensaios a experiência com o campo de visão ${ }^{13}$ e colocou no aparelho de som uma música muito boa, contemporânea e de qualidade. Na avaliação final desse encontro, falei que estaria deixando o grupo, pois sentia que realmente não tinha mais espaço como músico de violão. E Marcia respondeu assim: "mas você é o diretor musical do grupo, vai saber o que fazer!" E olhou-me de um jeito que compreendi perfeitamente bem o que ela queria dizer.

Saí daquele ensaio incomodado e motivado e fui pesquisar músicas e preparar o equipamento de som para o encontro seguinte. E a cada encontro apresentava um material musical novo e, quase sem precisar falar nada, apenas o olhando, Marcia foi me conduzindo a criar um repertório dialogado com a experiência dos atuantes no campo de visão e com as minhas próprias referências sonoras.

Senti que estava no caminho certo quando, em seguida, Marcia me convidou para colocar as músicas em suas aulas na graduação em Teatro e dei-me conta de que estava fazendo algo que, como músico, nunca havia feito antes e nem pensado que poderia fazer. $\mathrm{O}$ trabalho feito por mim era bem feito, mas sempre que tinha uma mínima falha, Marcia não deixava passar e comentava a respeito, discretamente, no final do trabalho, dizendo coisas do tipo: "mas àquela hora devia ter acontecido tal coisa..." e isso era o suficiente para eu preparar o material ainda com mais cuidados para o próximo encontro. Ou seja, ao mesmo tempo que ela conduzia seus alunos no campo de visão, ela me conduzia por novos desafios e aprendizados.

Eu, Agnes Sanfelici, entrei para o Grupo em 2015 e não tive muito tempo ao lado de Marcia, mas foi o suficiente para sentir a sua força transformadora, criativa e exuberantemente revolucionária. Ela sempre esteve ligada ao Teatro Comunitário do Canto, mesmo no período em que não estava presente fisicamente, no espaço físico da escola onde realizamos os ensaios.

13 Técnica de improvisação coletiva em coro desenvolvida pelo ator, diretor e professor de teatro na Universidade de Campinas, Marcelo Lazzaratto, que ministrou oficina extensiva. 
Sua força motriz e propulsora sempre esteve presente no grupo. Era ela quem promoveu os encontros, mobilizou outras figuras atuantes do teatro, organizou as diferentes oficinas que o grupo fazia. Sempre trouxe muito aprendizado e energias motivadoras para que o grupo pudesse seguir atuando e atuante.

No processo de criação conduzido por ela, o grupo realizava os ensaios ao mesmo tempo em que criava o roteiro da próxima peça teatral, somando dois processos: o campo de visão e nossas reflexões sobre a figura do analfabeto político, que ela trabalhou intensivamente a partir de situações e imagens. Ao mesmo tempo em que se procurava criar cenas, tecia-se longas discussões sobre quem era essa figura - o analfabeto político!

Foram momentos de muita criação e de muita angústia, mas que conduzia o grupo a dizer algo, a expressar o momento vivenciado. Alguns ensaios foram exaustivos e um deles em especial, em que cada membro do grupo repetia uma frase do poema "O analfabeto político", primeiro falava-se em voz baixa em diferentes entonações para as frases pronunciadas alternando tons, ritmos, volumes, intenções. O efeito dessas sonoridades foi, aos poucos, desvelando a figura do analfabeto político, ou ao menos, de como o grupo enxergava o analfabeto político e do quanto havia dele em cada um dos integrantes.

Na sequência desses ensaios, o sentido de analfabeto político não se limitou apenas ao desconforto e a críticas corriqueiras sobre figuras que representam a estagnação social, nem mesmo a figuras que vivem em suas bolhas discursivas negando a importância da política em nossas vidas. A questão aprofundou-se a tal ponto que o grupo conseguiu compreender a importância, cada dia mais emergente, de se organizar enquanto coletivo, de se encontrar enquanto identidade de teatro comunitário como, talvez, a única maneira de combater os "ratos" que voltam a invadir nossos países, cidades, casas e a destruir nossas esperanças e afetividades.

No final do ano de 2018 fizemos uma apresentação de processo na UDESC com a participação de convidados, ex-alunos estagiários, orientadores professores e estudantes da Universidade que foram recebidos na porta do Espaço II do Bloco Vermelho do CEART com uma música cantada pelo grupo. 


\section{CONSIDERAÇÕES FINAIS}

O objetivo do teatro comunitário é construir e compartilhar a arte teatral criada coletivamente no espaço da comunidade. Essa arte nasce dos múltiplos encontros de pessoas entre si com outras que desconhecem, mas se aproximam por meio do teatro, indicando que este é um convite para os interessados a tomar parte dessa utopia de proximidade. Através da ação de planejamento, proposta e produção teatral coletiva, membros de comunidades e de universidades desenvolvem múltiplos processos, abrindo espaço para emergências de suas capacidades cognitivas, criativas, de conscientização e de subjetividade.

A atuação de Marcia tornou possível a profícua relação entre a universidade e a comunidade, proporcionando necessárias sementes de inovação no campo da pedagogia teatral. Principalmente quando este campo é desafiado a proporcionar experiências relevantes que capacitem para o enfrentamento dos desafios cada vez mais complexos e diversos. Seu legado transcende as memórias organizadas nesse artigo, assim como dá visibilidade a propostas de teatro alternativas que se ampara em outros valores, diferentes do teatro profissional e comercial. 


\section{REFERÊNCIAS}

BORBA, Juliano. Teatro de Vizinhos: convívio, comunidade e celebração. Tese (doutorado)Universidade do Estado de Santa Catarina: Florianópolis, 2018.

FONSECA, Marilde Juçara da. Participação das Famílias na Instituição Pública de Educação Infantil: limites e possibilidades. Dissertação (Mestrado em Educação), Florianópolis, UFSC,2000.

NOGUEIRA, Marcia Pompeo. Teatro e Comunidade. In: FLORENTINO, Adilsom; TELLES, Narciso. Cartografias do Ensino de Teatro: das idéias às práticas. Uberlândia: EDUFU, 2008.

PINHEIRO TAVARES, Josanne. O teatro na relação escolacomunidade. Dissertação (mestrado) - Universidade do Estado de Santa Catarina: Florianópolis, 2007. 